\title{
LITERATO, PUBLICISTA Y SOLDADO: EL DIARIO DE JOSÉ VICENTE OCHOA EN LA GUERRA DEL PACÍFICO (1879-1880)*
}

\author{
WRITER, PUBLISHER AND SOLDIER: JOSE VICENTE OCHOA 'S \\ DIARY IN THE WAR OF THE PACIFIC (1879-1880)
}

\author{
Patricio Ibarra Cifuentes**
}

\begin{abstract}
El diario de José Vicente Ochoa, oficial del Estado Mayor General del ejército boliviano durante la Guerra del Pacífico, publicado en Sucre en 1899, permite conocer algunas de las reacciones culturales de los individuos enfrentados al estímulo de la participación directa en un conflicto bélico de grandes proporciones. Entre ellas la autovaloración e ideas de superioridad respecto de sus enemigos; legitimar la causa Aliada en general y boliviana en particular durante la guerra, la construcción, objetivación y negación de la alteridad chilena y el registro de las actividades cotidianas. En este caso, desde la perspectiva de un letrado de fines del siglo XIX, que a lo largo de su vida mezcló la actividad intelectual y literaria con el servicio público.
\end{abstract}

Palabras claves: Bolivia, Guerra del Pacífico, autodocumentos, testimonios de guerra, vida cotidiana.

José Vicente Ochoa's diary, an officer of the General Staff of the Bolivian army in the War of the Pacific, published in Sucre in 1899, allowing us to know some of the cultural reactions of individuals faced with the stimulus of direct participation in a largescale war conflict. Among them are self-assessment and ideas of superiority concerning their enemies, legitimize the Allied cause in general and Bolivian particularly during the war, the construction, objectification and denial of Chilean otherness and daily recording activities. In this case, from the perspective of a writer of the late nineteenth century, who throughout his life mixed intellectual and literary activity with public service.

Key words: Bolivia, War of the Pacific, self-documents, war testimonies, everyday life.

\section{Introducción}

El 14 de abril de 1879 José Vicente Ochoa inició las anotaciones de su Diario de la campaña del Ejército Boliviano en la Guerra del Pacífico, donde registró por encargo de la superioridad del Ejército de Bolivia, cuanto observó, supo por comentarios y su interpretación de ellos, a propósito del conflicto que enfrentó a Chile contra Perú y Bolivia por la posesión del salitre de Atacama y Tarapacá.

El escrito de Ochoa es un autodocumento, es decir, un registro testimonial escrito en primera persona creado bajo el paradigma de la modernidad, que supone el predominio del individuo y cómo se imagina y reconstruye a sí mismo (Mücke y Velázquez 2015: 14). Se trata de un ejercicio de memoria, a partir de la vivencia de episodios importantes tanto para él como para la sociedad a la que pertenecía, el que cambió su trayectoria vital pasada y condicionó la futura (Sautu 1999: 36). En general, los diarios se caracterizan por ser un registro de las experiencias y reflexiones de un individuo durante un tiempo específico, referidos a temáticas relacionadas con el acontecer cotidiano de su autor, aunque con un contenido diverso, pues incluye el relato de hechos y también sus apreciaciones al respecto (Mücke 2018: CXXVI). Son un espacio íntimo y subjetivo, donde el autor realizó un balance de su obrar, contextualizado por cuanto le rodea, centrándose en lo más importante para él (Sarabia, 1986). Del mismo modo, se trata de una reacción cultural instantánea y contemporánea al fenómeno narrado, en tanto existe un intermedio temporal acotado entre su elaboración y los hechos descritos, pues fueron realizados durante el desarrollo bélico mismo (Lorenz, 2008). Sin embargo, también pueden haber sido escritos ex post a partir de anotaciones contemporáneas a los hechos (Mücke 2018: CXXVII). Documentos como el de Ochoa, permiten recrear partes de "la gran historia", en torno a un fenómeno trascendente como lo es la Guerra del Pacífico, integrando elementos de "la

\footnotetext{
* Resultado Proyecto FONDECYT Iniciación No 11160136.

** Centro de Estudios Históricos (CEH), Universidad Bernardo O’Higgins. Santiago, Chile. Correo electrónico: patricio.ibarra@ubo.cl; https://orcid.org/0000-0002-7696-6173.
} 
pequeña historia" privada y cotidiana (González y Artaza 2015: 56).

En ese sentido, es posible señalar que la narrativa testimonial, proveniente de las naciones involucradas y también de terceros países junto con la historiografía, ha contribuido a que las sociedades recuerden, vulgaricen, mistifiquen y transformen la Guerra del Pacífico, al igual como ocurrió con otros enfrentamientos armados, en un referente cultural para las sociedades involucradas (Fussell, 2006: 121). De esa forma, permite la articulación de discursos, imaginarios y representaciones, que plantean interpretaciones que se materializan en posiciones reivindicativas, exculpatorias o acusatorias dependiendo de la nacionalidad desde donde se interprete el fenómeno (Rubilar 2015: 41), sobreviviendo a la modernidad, posmodernidad y la globalización derivando incluso en litigios diplomáticos de diverso origen y proyección (Ovando y González 2018: 80-81).

¿Qué caracteriza el Diario de José Vicente Ochoa? En primer lugar, fue elaborado por un miembro de la elite intelectual boliviana que por medio de la palabra escrita, materializada en expresiones artísticas (poemas), periodísticas (editor y colaborador de periódicos) y legal-administrativas (abogado y funcionario estatal), participó del desarrollo del conflicto como oficial de Estado Mayor y en la legitimación de la causa nacional de Bolivia contemporánea, entre 1879 y 1880 , y también posterior a los hechos mediante la publicación de otros escritos. Además del desempeño en distintos momentos de su vida en tareas diversas de la administración pública en los poderes Ejecutivo, Legislativo y Judicial de su país. Así, Ochoa fue protagonista y observador privilegiado de los hechos que narró. El Diario fue realizado por encargo del alto mando del Ejército boliviano, pese a ello contiene variadas apreciaciones personales respecto de lo acaecido. En paralelo, colaboró en los periódicos Boletín de Guerra del Ejército Boliviano, órgano oficial de esa entidad castrense, y en El Comercio de La Paz.

Además de la información que contiene respecto de las campañas del conflicto de 1879, el Diario permite explorar en diversas reacciones culturales en torno a la guerra, las que se aprecian transversalmente. En consecuencia, se trata de un producto donde se expresan variadas representaciones creadas a partir de la reelaboración personal y colectiva de estereotipos nacionales específicos en que se forjaron a partir de bagajes culturales, lecturas, técnicas, apreciaciones simplificadas, prejuicios, memorias históricas y juicios de valor (Cuevas, 2011: 2-9). A saber, justipreciar y explicar la causa de Bolivia y la alianza con Perú; la construcción, objetivación y negación de la alteridad chilena, anclada en el paradigma decimonónico del antónimo entre civilización y barbarie (Arellano, 2015: 72); además de la narración de parte de la cotidianidad del conflicto. Todo ello desde la superioridad moral autoasignada, a partir de la interpretación del estallido de la guerra como una agresión de Chile contra Bolivia, motivada por el interés de llevar adelante una acción de conquista de los territorios salitreros contra una nación débil, acto reñido con los principios del derecho de gentes contemporáneo, materializado en la ocupación arbitraria de Antofagasta el 14 de febrero de 1879. Esas expresiones tomaron forma de distinta manera según el momento de la campaña en el que fueron vertidas, relacionándose con el resultado fáctico de la campaña militar. En la medida que los chilenos fueron imponiéndose tanto en el mar como en tierra, el tono del relato, exitista y belicoso del inicio, se volvió luego sombrío y victimizado.

Por último, el Diario de Ochoa es el autodocumento boliviano relativo a la Guerra del Pacífico más extenso del que se tiene registro hasta el momento. Pese a ello, no relata ninguna batalla de la que Ochoa haya participado o presenciado directamente, con excepción de algunas escaramuzas entre buques chilenos y peruanos en la rada de Arica.

En la última década, parte de la producción historiográfica dedicada al conflicto de 1879 , ha rescatado las experiencias y subjetividades presentes en los autodocumentos de quienes participaron de la contienda. En general, se ha reconstruido y analizado sus características generales, además de fenómenos asociados a la cotidianidad, experiencia bélica y emocionalidad de los combatientes (Ibarra, 2017; Casanova, Díaz, Castillo, 2017; González, 2019, entre otras). De ese modo, el estudio de un escrito en particular no ha sido tema preferencial, en tanto registro de su tiempo condicionado por el contexto del momento en el que fue elaborado. Así, se podrá explorar en las perspectivas y representaciones, a escala humana, materializados en las páginas de un escrito elaborado por un protagonista de la Guerra del Pacífico mientras esta se desarrollaba.

\section{José Vicente Ochoa: literato y publicista}

Los datos biográficos disponibles de José Vicente Ochoa permiten identificarlo cómo un intelectual 
inquieto, materializado en su trabajo como literato y publicista, en tanto cultivó la poesía, además de la creación y colaboración en medios de prensa. Se sabe que estudió Derecho en la Universidad de San Francisco Xavier de Chuquisaca en Sucre. Obtuvo título de abogado en 1878 y se casó con Carmen Herrera.

Como hombre de letras, en la ciudad de La Paz participó en la fundación del Círculo Literario (1875), de la Sociedad 16 de Julio (1876), la Sociedad Gutiérrez (1883), entre otras (Ticlla, Calvo, Barnadas 2002: 381-382). Asimismo, fue miembro correspondiente del Ateneo de Lima y Santiago, además de la Sociedad de Escritores y Artistas de Madrid (Ochoa, 1892). También participó en entidades destinadas a la protección social tales como la Sociedad de Socorros Mutuos, los Obreros de la Cruz, San Vicente de Paul. Colaboró en varias publicaciones periódicas de La Paz, Sucre, Cochabamba y Potosí. En 1878 fundó la Revista Quincenal y en 1880 hizo lo propio con La Tribuna. (Ticlla, Calvo, Barnadas 2002: 381-382).

Como se señaló en líneas precedentes, entre 1879 y 1880 Ochoa ocupó un puesto en el Estado Mayor del Ejército de Bolivia y colaboró con $E l$ Boletín de la Guerra del Ejército Boliviano, cuyo jefe de redacción y editor responsable era Abdón Ondarza (Boletín de Guerra del Ejército Boliviano, 05/06/1879). En esta última publicación exaltó en varias oportunidades la alianza Perú-Boliviana, execrando a Chile y narrando algunos detalles de la campaña (Boletín de Guerra del Ejército Boliviano, 09/08/1879, 28/04/1880, 01/05/1880, 20/05/1880). Parte del material redactado en su Diario, fue usado por Ondarza sin citar la fuente (Ochoa 1899: 32). Asimismo, acompañó al general Hilarión Daza en la expedición al interior de Tarapacá llevada a cabo hacia fines de julio y comienzos de agosto de 1879 (Ochoa 1899: 88-107), como encargados de llevar el Diario de esta campaña (Boletín de Guerra del Ejército Boliviano, 09/08/1879). Del mismo modo, su intercambio epistolar con Jorge Mallo a propósito de la publicación por parte de este último de un folleto intitulado Alianzas americanas, vio la luz en El Comercio de La Paz donde se refirió al conflicto que se iniciaba (El Comercio 02/03/1879). A mediados de abril publicó en el mismo rotativo un "Himno Perú-Boliviano", en el que exhortó a los ciudadanos de ambos países a luchar mancomunadamente para derrotar a los viles piratas de Chile. A comienzos de mayo envió sus
"Impresiones de viaje", con comentarios respecto del periplo del Ejército boliviano desde La Paz a Tacna (El Comercio 12/04/1879 y 15/05/1879).

Terminada la participación efectiva de Bolivia en la guerra tras la batalla de Tacna (26/05/1880), en 1881 ejerció la docencia en Historia en el Colegio Ayacucho de La Paz (Ticlla, Calvo, Barnadas 2002: 381-382).

Entre sus trabajos históricos, biográficos y poéticos se cuentan: Poesías (1876), Borrones y perfiles (1885), Hojas al viento (1885), Paceños ilustres. El Dr. Cisneros (1888), Paceños ilustres. D. Evaristo Valle (1899), 16 de julio de 1809. Manifiesto de Goyeneche sobre el Primer Grito de Independencia Americana. Los libros de los Lanzas, su confiscación (1894) (Ticlla, Calvo, Barnadas 2002: 381-382). Respecto de sus poemas, se les ha señalado como característicos de la literatura boliviana del siglo XIX, en tanto privilegió el contenido en desmedro de la métrica, en temas como religión, moral, política y amor (Ortiz 2002: 76-79).

Mención aparte merece Abaroa. Semblanzas de la Guerra del Pacífico, biografía de Eduardo Abaroa, quien fue incorporado al panteón de los héroes bolivianos luego de fallecer en el combate de Calama (23/03/1879) tras seguir combatiendo contra los chilenos pese a intimársele rendición, escrita por el general chileno José Villagrán motivada por su amistad con Ignacio Abaroa, hermano del prócer, forjada mientras este oficial permaneció en Calama y Chiu-Chiu a cargo de las tropas que guarecían la zona. Allí, Ochoa publicó un breve resumen de la vida de Abaroa en modo de panegírico, donde destacó sus cualidades como hombre y combatiente que a su juicio le hacían acreedor del reconocimiento universal y un lugar en los anales de la historia, merced a su comportamiento frente al enemigo (Ochoa, 1892).

En paralelo a su vida intelectual, trabajó en la administración pública en los tres poderes del Estado de su país. Se desempeñó en juzgados y en distintos momentos de la década de1890 encabezó el Ministerio de Relaciones Exteriores, el de Instrucción, el de Hacienda e Industria, el de Instrucción y Colonización y de Instrucción y Fomento, durante los gobiernos de los presidentes Mariano Baptista y Severo Alonso. Además, fue Secretario de Embajada y Encargado de Negocios en Chile entre 1886 y 1889 (Ticlla, Calvo, Barnadas 2002: 382). En ese contexto defendió los intereses de su gobierno en la denominada "Reclamación de 
Chiu-Chiu", cuando Nieves de la Cruz de Rivas y Juan Francisco Rivas demandaron al Estado boliviano ante el Tribunal Arbitral chileno-boliviano, por los daños y perjuicios atribuidos a tropas altiplánicas a un establecimiento de amalgamación de esa localidad, durante la Guerra del Pacífico (Ochoa, 1887). Asimismo, en 1884, 1892 y 1894 ocupó un escaño en la Cámara de Diputados (Ticlla, Calvo, Barnadas 2002: 381-382).

\section{José Vicente Ochoa: soldado}

El nombre de José Vicente Ochoa se inscribe entre los miles de bolivianos, chilenos y peruanos que luego del estallido de la Guerra del Pacífico dejaron las actividades civiles para ocupar un lugar en los cuadros de sus respectivos ejércitos y fuerzas navales, con el objeto de cumplir con el mandato cívico-republicano decimonónico de defender a la Patria amenazada ante una agresión externa (Uribe de Hincapié 2004). En ese sentido, Ochoa y otros como él que de manera voluntaria prestaron servicio en la milicia, pueden ser considerados como soldados ciudadanos, pues se trató de individuos que sin experiencia bélica anterior, fueron la base desde la que se construyó cada Ejército (Ambrose 2000: 22). En definitiva, se trataba de sujetos que estaban dispuestos a arriesgar su vida por un principio (Keegan 2015: 241 ), en este caso, el bien superior del colectivo abstracto denominado nación cuyo valor era mayor al de una persona en particular, ofreciendo a la sociedad su bien más preciado, la vida, por el éxito de la causa.

En todo caso, debido a la composición social y étnica de las tropas aliadas, y en especial, las bolivianas, formadas por mestizos e indígenas provenientes en su mayoría del bajo pueblo, Ochoa fue la excepción debido a su formación profesional y trabajo intelectual. De allí que haya sido empleado en el Estado Mayor del Ejército boliviano. Por esa razón, perteneció al campamento letrado, es decir, al grupo de productores de contenidos escritos relacionados con el desarrollo del conflicto por medio de los que se satisfizo la necesidad de información e interpretaciones de un público contemporáneo y posterior a los hechos (Ibarra 2015: 175).

No existen antecedentes respecto del periodo exacto de su permanencia en el Ejército boliviano más allá de las fechas consignadas en su Diario. A partir de allí, se deduce que se integró a la milicia en abril de 1879 y dejó las filas después de mayo de 1880, tras la derrota aliada en Tacna.

\section{El Diario de la campaña del Ejército Boliviano en la Guerra del Pacífico}

El Diario de Ochoa se vincula con la práctica del registro regular de pensamientos y actividades cotidianas, común entre los individuos letrados del siglo XIX tanto europeos como americanos. En este caso, el escrito combina la esfera privada y pública pues mezcla el relato de un evento trascendente para sus contemporáneos y la posteridad, con sus apreciaciones personales (Mücke 2018: CXXX). En efecto, en la anotación del 7 de noviembre de 1879, al momento que se inició la marcha del Ejército boliviano desde Tacna a Tarapacá para lo que debía ser el enfrentamiento contra los chilenos que desembarcaron en Pisagua el 2 de ese mes, Ochoa señaló que inicialmente fue escrito por encargo y que desde ese momento tendría un énfasis personal, pues las circunstancias de la campaña que se iniciaba impedían realizar comentarios extensos acerca de las actividades diarias y, más importante aún,

"los acontecimientos que se desarrollan y se preparan nos sugieren la idea de juzgarlos con amplia libertad y criterio, y en reserva, a fin de que el Diario no pueda ser leído ni por el General Daza ni por ningún otro individuo del Estado Mayor" (Ochoa 1899: 183).

El documento se inicia con una "Advertencia de la Edición" en donde se asegura que no pudo ser completado pues Ochoa falleció antes de revisarlo y "darle mayor extensión". Más aún, el editor asegura que la intención del autor era agregarle una conclusión y publicarlo como parte de su obra (Ochoa 1899: II-III). Asimismo, se asegura que el Diario "fue llevado por su autor con fidelidad estricta y a medida que se producían los acontecimientos que en este libro se refieren". Del mismo modo, el escrito fue publicado sin modificación alguna "conservando hasta sus imperfecciones de estilo" para que no fuera alterada la "sinceridad del relato, ni la verdad de las impresiones" (Ochoa 1899: II). Es admisible señalar que la primera edición vio la luz en Sucre en 1899 mediante la Tipografía y Librería Económica. En 2012 La Casa del Libro Viejo de Lima lo reimprimió. 
El Diario en cuanto tal comienza con una "Introducción", la que presenta los antecedentes de la guerra. Allí, Ochoa caracterizó la ocupación de Antofagasta que dio inicio a la guerra en febrero de 1879 , a partir del problema suscitado por la cuestión del salitre, como la manifestación de la guerra de "conquista", reñida con el derecho de gentes, llevada adelante por Chile contra Bolivia, lo que se constituyó como un insulto a "humanidad -adelanto, al hombre- civilización"; señalando con ello una de las ideas fuerza de su escrito: la conducta bárbara de Chile y los chilenos durante la contienda. En ese sentido, se utilizó la dicotomía civilización-barbarie, con el objeto de explicar las diferencias entre aliados y chilenos y como forma de medición de cada sociedad (Arellano 2015: 72). Asimismo, aseguró que se enfrentaron dos entidades de distinta índole y valoración. Por una parte, Chile que tenía de su lado la fuerza bruta y la ignominia, materializada en su orgullo por su flota naval y su "pirática hazaña". Por otra, Bolivia "rodeada de las simpatías del mundo y de la causa de la justicia", aunque "débil en fuerzas materiales, fuerte en valor y heroísmo". De ese modo, la lucha en el Pacífico sur se transformó en la disputa de las fuerzas del bien y del mal, de la legitimidad contra la fuerza, de la justicia del derecho de gentes y el progreso contra la barbarie, anclado en el paradigma civilizatorio de la modernidad decimonónica que tuvo su correlato en otras manifestaciones contemporáneas tales como el periodismo, literatura y, posteriormente, en la historiografía. De la misma manera, la causa nacional se fundó en la legitimidad del "honroso encargo de la patria a salvar el territorio hollado por los falsos reivindicadores" (Ochoa 1899: 1-2), aludiendo a la idea planteada por Chile relativa a que ocupó Antofagasta en tanto era un territorio que por derecho le pertenecía, producto de los atropellos cometidos contra la población chilena y de la violación por parte de Bolivia del tratado de 1874.

El relato se inició en La Paz el 14 de abril de 1879, a dos meses del desembarco chileno en Antofagasta y a nueve días de la declaración de guerra por parte de Chile a Perú, tras que se develara al gran público la existencia del tratado de alianza defensiva que unía a peruanos y bolivianos desde 1873, situación no mencionada en el Diario. Sus anotaciones culminaron el 23 de mayo de 1880, tres días antes de la derrota del ejército Perú-Boliviano en Tacna, la que implicó en la práctica el fin de la cooperación entre ambos países en tanto las fuerzas de Bolivia se retiraron hacia el altiplano, dejando a la nación incásica a su suerte. En la práctica, narró toda la participación boliviana en la guerra, dando cuenta de la salida y viaje de las tropas a Tacna (abril de 1879), la excursión a Tarapacá del alto mando boliviano (julio-agosto de 1879), la fallida expedición al sur tras el desembarco de los chilenos en Pisagua (noviembre de 1879) y la extensa estadía en Tacna hasta la batalla del Campo de Alianza (noviembre de 1879 a mayo de 1880). Ochoa afirmó que sus apuntes fueron "escritos a vuela pluma, muchas veces sobre el lomo de bestia o en medio del vivac de la campaña y quizá tras del fragor del combate" (Ochoa 1899: 3). Además reprodujo distintos documentos asociados a los hechos representados, ya sean cartas, telegramas, partes de batalla, proclamas, entre otros. El Diario fue elaborado con plena conciencia de su valor como testimonio contemporáneo de un fenómeno trascendente, pues asume que será "de alguna utilidad después de la tormenta de la guerra, para la historia de ella" (Ochoa 1899: 3).

\section{¡Viva la alianza Peruboliviana!: Bolivia, la causa aliada y los chilenos}

Ochoa celebró y exaltó la alianza formada por Perú y Bolivia, asumiendo que aquella era la causa de la justicia y la hermandad entre dos países con un pasado, presente y futuro común. En la introducción del Diario señaló: "No haremos más que apuntar el noble y brillante proceder peruano para con su hermana la República de Bolivia" (Ochoa 1899: 3 ), en tanto tras el fracaso de las negociaciones diplomáticas entre Perú y Chile llevadas a cabo en marzo de 1879, la nación incásica reconoció la existencia del tratado de 1873 con Bolivia y Chile le declaró la guerra el 5 de abril. Así, ambas naciones se encontraban juntas y no dudó en aunarlas metafóricamente bajo la más importante de las deidades incas: Inti (el Sol), en evidente alusión al origen mítico y pertenencia a esa cultura precolombina. El 15 de abril de 1879 exclamó: "¡Hurra Hijos del Sol! ¡Viva la alianza Peruboliviana!” (Ochoa 1899: 8). Del mismo modo, a propósito de un tiroteo entre los buques Pilcomayo del Perú y O'Higgins de Chile en Arica, anotó a comienzos de octubre que la nave peruana "antes y después del combate" enarboló los pabellones aliados, como "símbolo precioso de la sagrada alianza que estrecha a las Repúblicas hermanas" (Ochoa 1899: 152). 
Como se sabe, entre abril y octubre de 1879 la guerra se desarrolló fundamentalmente en el mar. Los bolivianos, al no poseer buques con los cuales participar de las operaciones, permanecieron como espectadores de los hechos acantonando sus fuerzas en Tacna. La noticia del hundimiento de la corbeta chilena Esmeralda por el monitor peruano Huáscar en Iquique (21/05/1879), fue interpretado por Ochoa como un triunfo aliado. Afirmó de manera altisonante:

"un hecho brillante abre la campana de las fuerzas Perú-bolivianas, cuando, recién se rompen los fuegos", agregando que "las victorias de la justicia son como esta, que no necesitan comentarios" (Ochoa 1899: 44).

Sin embargo, en esa misma jornada algunas millas al sur, en Punta Gruesa, la goleta chilena Covadonga dio cuenta de la fragata blindada Independencia, con lo que el poder naval peruano se redujo drásticamente. El 23 de mayo anotó que una vez conocida la noticia "A la alegría de ayer ha sucedido una letal tristeza que raya en desesperación" (Ochoa 1899: 45) y sentenció "el Perú por sí mismo, se puede decir, ha cortado el brazo izquierdo de su armada", en tanto el acorazado encalló mientras perseguía a la goleta (Ochoa 1899: 45), aisló, de ese modo, la responsabilidad de la derrota en los peruanos y no en la alianza.

Sin embargo, en las semanas y meses posteriores el tono triunfalista de Ochoa retornó merced a las incursiones del Huáscar contra intereses chilenos. El 30 de agosto de 1879 se refirió al duelo artillero entre el monitor y las baterías chilenas del puerto de Antofagasta, señalando que la victoria correspondió al primero pues se trató de "un nuevo triunfo sobre el atolondrado Chile" (Ochoa 1899: 121). Asimismo, el 10 de septiembre de 1879 celebró la huida del transporte peruano Chalaco del blindado chileno Blanco Encalada, afirmando que este

"quiere imitar al Huáscar, y solo consigue hacer la caricatura de la guerra de crucero con la que la invencible nave hermana ha dado ya tantas glorias a la causa de la Alianza" (Ochoa 1899: 132-133).

El nacionalismo católico, que reúne la religión, la moral, la fe con los intereses políticos (McEvoy 2004: 85), también se apoderó de la pluma de
Ochoa. A propósito de los rumores de una pronta incursión chilena contra Iquique, aseveró que "La Providencia nos ayuda" anotó el 4 de julio de 1879 y agregó "Felizmente los chilenos han demostrado hasta ahora su torpeza. Tenemos nosotros la justicia y tendremos también el triunfo" (Ochoa 1899: 74), subrayando la idea de la lucha contra el bien y el mal donde la causa boliviana era justa y legítima, en este caso invocando la protección divina. Sin embargo, la captura del monitor y la muerte de su comandante Miguel Grau el 8 de octubre de 1879, a manos de los blindados chilenos, le causó desazón. El 9 de octubre escribió: "Nadie puede creer que Dios castigue a dos pueblos que defienden la justicia, la honra y la soberanía, con una desgracia semejante. Imposible!". Días más tarde, el 14 de octubre, realizó un sentido panegírico a la tripulación de la nave asegurando que

"Nos faltan lágrimas para llorar a ese puñado de valientes que han sucumbido en el Huáscar y no tenemos palabras suficientes para ensalzar el glorioso martirio que han sufrido con el valor de los mártires y la serenidad de los héroes" (Ochoa 1899: 158-159).

En todo caso, llamó a seguir en la lucha teniendo como referente al malogrado buque: "Nos queda su memoria, como digno ejemplo para vengar la pérdida del infortunado Huáscar" (Ochoa 1899: 159).

Empero los reveses militares continuaron. Iniciadas las operaciones chilenas en Tarapacá en noviembre de 1879 , los triunfos favorecieron a los invasores del sur como ocurrió en Pisagua y Junín (02/11/1879), Pampa Germania (06/11/1879) y Dolores (19/11/1879). Sin embargo, se produjeron dos acciones en que se impusieron las fuerzas aliadas: Tarapacá (27/11/1879) y Tambillo (06/12/1879). En el primero de ellos, una victoria pírrica, las tropas aliadas luego de imponerse se replegaron hacia Arica dejando la zona y, más importante aún, los yacimientos salitreros en manos de los chilenos. $\mathrm{Al}$ respecto, Ochoa mencionó que el hecho era más honroso para el Perú pues "la fuerza boliviana que allí había combatido era solo el batallón Loa" (Ochoa 1899: 212). De la segunda, una acción menor entre destacamentos de caballería, aseguró que una partida boliviana "derrotó a una fuerza importante de Chile" (Ochoa 1899: 265) dejando algunos muertos y tomando prisioneros. 
Las derrotas sufridas hicieron aflorar las diferencias entre los aliados, que a comienzos de 1880 ya eran evidentes. Ochoa anotó el 8 de febrero que el carnaval anual celebrado previo al periodo del calendario católico denominado como cuaresma

\begin{abstract}
"se presenta muy malo, tanto por la guerra, cuanto por las disensiones entre peruanos y bolivianos que cada día se acentúan más" (Ochoa 1899: 270).
\end{abstract}

Por otra parte, el Diario exaltó las virtudes cívicas y patrióticas de los bolivianos, materializados en la adhesión a la causa y la disposición a sacrificarse por ella. En la introducción Ochoa sentenció que "El soldado boliviano no cree ir a la guerra, sino a la victoria, porque tiene seguridad de ella" (Ochoa 1899: 4). Asimismo, el 3 de julio de 1879 luego de una ceremonia de entrega de armas aseguró que "Es indescriptible el entusiasmo de cada soldado al verse con su rifle. Parece que comprendiera que con esa arma ha de salvar la patria, vengando su honra y recuperando su territorio". Finalmente acotó

"Que vayan bien nuestros soldados, que marchan tan entusiastas a la pelea y el triunfo, debiendo burlar la voraz persecución chilena" (Ochoa 1899: 72-73).

Respecto de un grupo de hombres que aun enfermos marcharon para reunirse con el Ejército señaló: "Honor al soldado boliviano que tan bien sabe cumplir las leyes del deber y del patriotismo, que son leyes de la naturaleza y de Dios". Y agregó que lo hicieron motivados "Con la entera fe del ciudadano que marcha al puesto de honor" (Ochoa 1899: 37). De la misma manera, relató que en el Regimiento Libres del Sud 3º, venía "la juventud más distinguida del Sud, que ha hecho la abnegación sublime de abandonar patria y familia, para correr vestido con la jerga del soldado tras la defensa nacional" (Ochoa 1899: 39), subrayando en la procedencia y alcurnia de quienes integraron esa unidad. Pese a lo anterior, tras los primeros reveses aliados luego del avance chileno en Tarapacá durante noviembre, criticó las deserciones de algunos efectivos "de varios soldados del Regimiento Libres del Sud y un capitán del mismo!" (Ochoa 1899: 199). Algo similar ocurrió a fines de enero de 1880 cuando recibió la información que "con las marchas y contramarchas la tropa está descontenta y hay mucha deserción" (Ochoa 1899: 267).

En paralelo a enaltecer la alianza Perú-Boliviana en general y a Bolivia en particular, Ochoa construyó y colocó la alteridad chilena en contraposición, basándose en la justicia de la causa y el compromiso ciudadano de quienes defenderían la patria amenazada. El Diario articuló un relato de diferenciación con sus enemigos del sur, a partir de la creación de una imagen negativa y despreciativa, categorizándolos como moralmente inferiores debido a sus intenciones espurias y comportamiento, señalándolos como alejados de la conducta de las naciones civilizadas, tanto en lo referido al estallido de la guerra como durante el desarrollo de esta. Así entonces, Chile y los chilenos fueron convertidos en un "otro" ajeno y desconocido, negándoles la posibilidad de ser considerados como grupo o individuos que poseían la misma condición de apego al decoro y el derecho atribuida para sí mismos reforzando, de paso, la identidad propia (Tiapa 2011: 390-400).

Comentando la reacción en Chile a propósito del hundimiento de la Esmeralda en Iquique el 21 de mayo de 1879 , positiva en tanto se consideró heroico el no rendirse ante un enemigo superior como lo fue el Huáscar, Ochoa aseveró el 10 de junio de 1879 que "han dado por triunfo suyo el descalabro de la Esmeralda" y agregó "No tenían otra cosa que hacer. Es ya costumbre entre ellos, festejar sus derrotas" (Ochoa 1899: 60). Del mismo modo, el 14 de septiembre de 1879 anotó que circularon noticias relativas a que una partida de tropas chilenas se internaron en el desierto y que en San Pedro, aprovechando la ausencia de los vecinos, lo quemó, robó y redujo a escombros "dejando en la orfandad y la miseria a muchas familias" (Ochoa 1899: 135). A propósito de la captura del Huáscar, el 14 de octubre de 1879 señaló que la prensa chilena "con la villanía que los caracteriza", aseguró que la nave "izó bandera blanca", y se rindió, considerado ofensivo al honor y bizarría de sus marinos, y por extensión a los peruanos y sus aliados. A renglón seguido afirmó: "Qué infames! No merecen más que el desprecio universal", reafirmando que Chile debía ser execrado por el resto de las naciones (Ochoa 1899: 158). En esa misma línea, en el Diario se imputa a los chilenos actos reñidos con el derecho de gentes y de guerra. Por ejemplo, al consignar lo ocurrido en Mollendo, entre el 9 y 12 de marzo de 1880, donde desembarcaron 
para inutilizar las instalaciones portuarias, lo que devino en indisciplinas, disturbios y destrucción de edificios públicos, anotó:

"El incendio de Mollendo es un hecho. Los chilenos han robado y cometido los actos más bárbaros al retirarse" (Ochoa 1899: 290).

\section{"Estamos acampados al raso": La cotidianidad del Ejército boliviano}

Los individuos que participaron de las operaciones militares durante la Guerra del Pacífico, asumieron su rol como soldados adaptándose a la vida de cuartel y de campaña que se transformaron en su nueva cotidianidad. En ese contexto, desarrollaron habilidades y estrategias de sobrevivencia y de relación con sus pares apropiándose de conductas y saberes específicos de la vida castrense, proveyéndoseles de los conocimientos y competencias para enfrentarse a la realidad concreta de la campaña y el combate (Heller, 1987: 22). Así, al formar parte de la milicia se hicieron cargo de una cultura caracterizada por valores, creencias, actitudes y normas propias de la profesión de las armas (Gutiérrez 2002: 3), todo esto estaba regulado por los mecanismos de control establecidos en leyes y reglamentos que les constituye como un grupo especial en la sociedad, del que se espera un comportamiento determinado (Zamora 2005: 135).

El Diario de Ochoa recoge algunas de las condiciones de la vida y las actividades realizadas por las tropas bolivianas mientras duró su periplo por tierras del Perú, con ello también se enalteció el sacrificio, propio y de sus camaradas, hecho por la Patria. Por ejemplo, en los comienzos de la campaña, hacia fines de abril de 1879 anotó que durante la marcha a Tacna, al permanecer en la zona altiplánica de Uchusuma "todos estamos acampados al raso" (Ochoa 1899: 14). Ya acuartelados en Tacna, con indisimulado orgullo, aseguró que "el ejército sigue disciplinándose, admirando al pueblo y autoridades de Tacna por el orden y moral con que se maneja" (Ochoa 1899: 23). En todo caso, el tedio producto de la inactividad y la incerteza de combatir a los chilenos comenzó a apoderarse de Ochoa y el Ejército boliviano. A inicios de agosto de 1879 aseguró que "la inercia y la flojedad de esta guerra, es lo que la caracteriza claramente" (Ochoa 1899:109). Una de las constantes de la vida de campaña fue la continua propagación de rumores o bolas, como se les denominó coloquialmente, nacidos a partir de informaciones incompletas y conjeturas respecto del devenir del conflicto. Ochoa estaba acostumbrado a ellos y no dio crédito a todo lo que se dijo, como lo anotó del 24 de mayo de 1879:

"Muchas noticias corren que las consi-
deramos bolas, razón por la que no las
apuntamos hasta convencernos de su
verdad" (Ochoa 1899: 46).

Con el paso del tiempo los alimentos comenzaron a escasear. El 22 de septiembre de 1879 Ochoa aseguró que "son repetidas las quejas que se recibe en el Estado Mayor de los jefes de nuestros cuerpos escalonados en Tarapacá, por falta de diarios y provisiones", situación que a su juicio era responsabilidad de los peruanos quienes, según lo establecido en el Tratado de Alianza, se comprometieron "al mantenimiento de parte de nuestras tropas". Del mismo modo, se produjeron numerosas solicitudes de licenciamiento provocadas por "nuestra lamentable y pasiva residencia en Tacna" (Ochoa 1899: 144). En noviembre de 1879, al salir de Arica en busca de los chilenos tras el inicio de la invasión a Tarapacá, las tropas se encontraron con la rudeza del clima desértico y "el sofocante y seco calor de esta región" que "han traído el cansancio a muchos individuos", además de acampar a la intemperie "llenos de calamidades y desprovistos de todo" (Ochoa 1899: 185). A inicios de mayo de 1880, de vuelta en Tacna y a la espera de los chilenos que avanzaban por Moquegua, Ochoa anotó que aún permanecían a las afueras de la ciudad y que "la escasez de agua es el principal inconveniente con que se tropieza" (Ochoa 1899: 306).

Dos fueron los momentos en que Ochoa y sus camaradas comprendieron que la espera había terminado y habrían de enfrentar a los chilenos. El primero fue en noviembre de 1879. El 8 de ese mes, producto del desembarco de Pisagua (02/11/1879), Ochoa aseguró que:

"Al fin se realiza la anhelada marcha del Ejército Boliviano de Tacna, que estaba ya descontento por su inacción y que no veía la hora de ir a cumplir su deber al frente del enemigo" (Ochoa 1899: 184). 
Sin embargo, las ansias de combatir en Tarapacá fueron frustradas pues solo llegaron hasta la quebrada de Camarones donde por orden del general Daza debieron devolverse sin pelear. El 16 de noviembre, afirmó que "esta vergonzosa retirada estuvo ya resuelta y se le ha querido justificar con un consejo de guerra". La situación, calificada por Ochoa como una "humillante resolución" (Ochoa 1899: 188), se conoce como la retirada de Camarones (Quejerazú 1992, 338-341).

El segundo fue en mayo de 1880, cuando en las inmediaciones de Tacna el Ejército Perú-Boliviano se atrincheró para combatir a sus adversarios. El 22 de mayo, cuatro días antes de la batalla del Campo de Alianza, Ochoa escribió:

“Viva la Alianza! El entusiasmo en el
Ejército es indescriptible. Campero reco-
rre la línea, proclamando a cada cuerpo
particularmente (...) Se conoce que se ha
retirado, después de examinar nuestras
posiciones” (Ochoa 1899: 313).

Sin embargo, aquello era incorrecto. Los chilenos enfrentaron y derrotaron a los aliados, quedando Ochoa y Bolivia fuera de la guerra.

\section{Conclusión}

El Diario de Ochoa presenta la reflexión in situ respecto de su experiencia bélica desde la perspectiva de un letrado que enlistado como oficial de Estado Mayor, se relacionó y tuvo acceso privilegiado a los directores de la guerra bolivianos entre 1879 y 1880 .

En su autodocumento, constituido como un híbrido entre crónica oficial realizada por encargo del alto mando del Ejército de Bolivia y escrito personal, Ochoa caracterizó las motivaciones de Bolivia y Chile en el conflicto de 1879 , señalando a este último país como el responsable de la confrontación, preparada de manera premeditada y ejecutada de forma alevosa y artera. Así, trazó la frontera entre el derecho y la ilegalidad, la justicia y la sinrazón, finalmente, entre la civilización y la barbarie.
En ese sentido, el Diario creó un relato funcional, adscrito y concordante con el discurso contemporáneo desde un punto de vista patriótico y nacionalista, laico y católico, contemporáneo a los hechos, que hizo propia la causa boliviana, la alianza con Perú y la exaltación de las virtudes cívicas de quienes tomaron parte activa de las operaciones militares durante la Guerra del Pacífico, el que se reprodujo en la prensa, la literatura, las artes plásticas contemporáneas, el que a su vez fue sacralizado por la acción de la historiografía de fines del siglo XIX y del XX, transformándose en el canon de interpretación predominante en Bolivia, y con matices también en el Perú, respecto del conflicto. Aquello, devino en la construcción de los chilenos como un 'otro', el que debía ser negado, execrado y castigado por sus actos.

Del mismo modo, el Diario de Ochoa permite distinguir dos fases en la reacción en Bolivia respecto de la guerra. La ilusión y certeza de la victoria fundada en la justicia de la causa al inicio de las hostilidades, la que se transformó en desencanto e incertidumbre ante las constantes derrotas de los aliados durante la campaña naval y en Tarapacá.

Asimismo, presenta parte de la cotidianidad del conflicto, relatando las condiciones de vida que tuvieron todos quienes fueron parte de la hueste que hizo la campaña contra Chile, habiendo de enfrentar el clima agreste del desierto, la monotonía del campamento, la carestía de alimentos y la incertidumbre provocada por la falta de información concreta respecto del devenir de la guerra, situaciones que se repitieron entre los combatientes y otros partícipes del conflicto de 1879 independientemente de su nacionalidad.

En definitiva, el Diario de José Vicente Ochoa es un escrito que representa parte importante de las manifestaciones culturales generadas a partir del inicio de la Guerra del Pacífico, las que se vinculan con las inquietudes de un individuo que, haciendo propio el mandato cívico y patriótico de colaborar en la defensa de su país ante un conflicto externo, puso su talento personal y disposición al servicio de la causa de Bolivia. 


\section{Referencias Citadas}

\section{Periódicos}

Boletín de guerra del ejército boliviano (Tacna, 1880).

El Comercio (La Paz, 1879).

\section{Libros y artículos}

Ambrose, S.

1997 Citizen soldiers. The U.S. Army from the Normandy beaches to the Bulge to the surrender of Germany. June 7, 1944-may 7, 1945, New York.

Arellano, J.

2015 'El pueblo de 'filibusteros' y la 'Raza de malvados': discursos nacionalistas chilenos y peruanos durante la Guerra del Pacífico (1879-1884)", Diálogo Andino, 48: 71-83.

Casanova, F., Díaz, A. Castillo, D.

2017 Tras los pasos de la muerte. Mortandad en Tacna durante la Guerra del Pacífico, 1879-1880, Historia, 50: 399-441. Cuevas, Y.

2011 "Representaciones sociales en la prensa: aportaciones teóricas y metodológicas". Sinética. Revista electronica de educación, 36: 1-19.

Fussell, $\mathrm{P}$.

2006 La Gran Guerra y la memoria moderna, Turner. Madrid. González, C.

2019 "Cicatrices del alma. Las consecuencias emocionales de la experiencia bélica de los combatientes chilenos en la Guerra del Pacífico (1879-1884)", Revista de Historia, 26, 1:7-28.

González, S., Artaza, P.

2015 "Cateando la palabra. La construcción de nuevos archivos sobre la sociedad del salitre". Diálogo Andino, 46, 55-70.

Gutiérrez, O.

2002 Sociología militar. La profesión militar en la sociedad democrática, Editorial Universitaria, Santiago.

Heller, A.

1987 Sociología de la vida cotidiana, Ediciones Península, Barcelona.

Ibarra, $\mathrm{P}$.

2018 “"Narro lo que vi’: La Guerra del Pacífico en primera persona". En La Guerra del Pacífico 1879-1884: ampliando las miradas en la historiografía chileno-peruana, editado por Chaupis, J. y Tapia, C., pp. 213-233, Legatum Editores, Santiago.

Ibarra, P.

2015 En Pacocha y Lima: dos epístolas de Alberto del Solar durante la Guerra del Pacífico (1880-1881), Revista de Historia y Geografía, 33: 175-188.

Keegan, J.

2015 La máscara del mando. Un estudio sobre el liderazgo, Turner, Madrid.

Lorenz, F.

2008 "Es hora que sepan" La correspondencia de la guerra de Malvinas: otra mirada sobre la experiencia bélica de 1982, Páginas 1: 111-129.

McEvoy, C.

2004 De la mano de Dios. El nacionalismo chileno y la Guerra del Pacífico, 1879-1881, Histórica XXVIII.2: 83-136.
Mücke, U. y Velázquez, M. (Editores).

2015 Autobiografía del Perú republicano. Ensayos sobre historia y narrativa del yo, Biblioteca Nacional del Perú, Lima.

Mücke, U

2018 "The diary of Heinrich Witt and autobiographical writing". En The Diary of Heinrich Witt, editado por Mücke, U. pp. cxxxiii-cxli, Brill, Leiden.

Ochoa, J.

1887 Reclamación de Chíuchíu. Contestación al alegato de prueba de la parte demandante y alegato por la de Bolivia, Imprenta Cervantes, Santiago.

Ochoa, J.

1892 Abaroa. Semblanzas de la Guerra del Pacífico, Imprenta y Litografía Boliviana, La Paz.

Ochoa, J.

1899 Diario de la campaña del ejército boliviano en la Guerra del Pacífico, Tipografía y Librería Económica, Sucre.

Ochoa, J.

2012 Diario de la campaña del ejército boliviano en la Guerra del Pacífico, La Casa del Libro Viejo, Lima.

Ortiz, R.

2002 "Aproximaciones a la literatura decimonónica en Bolivia”. En Hacia una historia crítica de la literatura en Bolivia. Tomo II. Hacia una geografía del imaginario, editado por Paz Soldán, A. pp. 58-88, PIEB, La Paz.

Ovando, C., González, S.

2018 "El papel de la paradiplomacia entre el norte de Chile y el sur del Perú: antecedentes históricos, limitaciones institucionales y nuevos desafíos 'Posfallo de la Haya". Diálogo Andino, 55, 79-91.

Querejazú, R.

1992 Guano, salitre, sangre. Historia de la Guerra del Pacífico (La participación de Bolivia), Librería Editorial "G.U.M.", La Paz.

Rubilar, M.

2015 "Prensa e imaginario nacional: la misión social de los actores subalternos regionales durante la Guerra del Pacífico". Diálogo Andino, 48, 41-53.

Sarabia, B.

1986 "Documentos personales: historias de vida", en $E l$ análisis de la realidad social. Métodos y técnicas de investigación social editado por García, M., Ibáñez, J. y Alvira, F. pp. 187-208, Alianza, Madrid.

Sautu, R.

1999 El método biográfico. La construcción de la sociedad a partir del testimonio de los actores, Editorial Belgrano, Buenos Aires.

Tiapa, F.

2011 "Identidad, alteridad y relaciones interétnicas en las fronteras de la Modernidad. Una aproximación desde la teoría antropológica". Fermentum, 21, 62, 384-414.

Ticlla, J.; Calvo, G.y Barnadas, J.

2002 Diccionarios Histórico de Bolivia L-Z, Grupo de Estudios Históricos, Sucre.

Uribe de Hincapié, M.

2004 El republicanismo patriótico y el ciudadano armado, Estudios Políticos, 24, 75-92.

Zamora, I

2005 "La importancia de la vida cotidiana en los estudios antropológicos". Revista Líder, 14, 123-143. 